\title{
ADMINISTRAÇÃO PÚBLICA: LEI DE RESPONSABILIDADE FISCAL E A CONTROLADORIA
}

Marco Aurélio Kalife ${ }^{1}$

\section{RESUMO}

Este artigo apresenta a evolução dos fatos mais importe antes que caracterizaram o Controller e o planejamento orçamentário antes, durante e depois da Lei de Responsabilidade Fiscal. Mostra-se a necessidade do planejamento orçamentário e procura-se identificar as razões pelas quais o administrador público estará cada vez mais direcionado ao planejamento.

O artigo conclui com uma avaliação cautelosamente otimista acerca das perspectivas da administração municipal brasileira e do Controller na nova visão orçamentária, voltada ao cumprimento da Lei de Responsabilidade Fiscal.

Palavras-chave: Controller, Lei de Responsabilidade Fiscal, orçamento público, planejamento orçamentário, previsão orçamentária, Comportamento do Gestor Público.

\section{ABSTRACT:}

This article presents the evolution of the facts most important that they had characterized the Controller and the budgetary planning before, during and after the law of Fiscal responsibility. Necessity of the budgetary planning reveals to it and is looked to identify to the reasons for which the public administrator will be each directed time more to the planning.

The article concludes with a cautiously optimistical evaluation concerning the perspectives of the Brazilian municipal administration and the Controller in the new budgetary vision consonant the Law of Fiscal Responsibility.

\footnotetext{
${ }^{1}$ Mestre em controladoria UFRGS e Professor no Centro Universitário La Lalle.
} 
Key words : Controller, Law of Fiscal Responsibility, public budget, budgetary planning, budgetary forecast, , behavior of public-resource managers

\section{Introdução}

A Lei de Responsabilidade Fiscal - Lei Complementar № 101, de 04 de maio de 2000, publicada no Diário Oficial da União de 05.05.2000 - estabelece normas de finanças públicas voltadas para a responsabilidade na gestão fiscal e tem sido amplamente debatida em todo o País, com grande repercussão na imprensa. Antes da Lei, a administração pública, de modo geral, não tinha o mesmo grau de compromisso com o orçamento. Gastava-se dinheiro, muitas vezes contando com verbas futuras incertas. A partir da Lei de Responsabilidade Fiscal - LRF, esse ato passa a ser ainda mais temerário porque agora o gestor gasta dinheiro e orçamento. Se a despesa não estiver prevista no orçamento, serão necessários cortes e ajustes mais adiante, esclarece (SILVA, 2002). ${ }^{2}$

A Constituição Federal, ao consagrar o princípio da moralidade administrativa como vetor da atuação da administração pública, igualmente consagrou a necessidade de proteção à moralidade e há responsabilização do administrador público, amoral ou imoral. Anota Sobrinho (2002): Difícil de saber por que o princípio da moralidade no direito encontra tantos adversários. A teoria moral não é nenhum problema especial para a teoria legal. As concepções na base natural são analógicas. Por que somente a proteção da legalidade e não da moralidade também? A resposta negativa só pode interessar aos administradores ímprobos. Não à Administração, nem à ordem jurídica. O contrário, seria negar aquele mínimo ético mesmo para os atos juridicamente lícitos. Ou negar a exação no cumprimento do dever funcional.

\footnotetext{
${ }^{2}$ Lino Martins Silva Graduado em Ciências Contábeis e Direito, é professor adjunto da Faculdade de Administração e Finanças da UERJ, lecionando Contabilidade Pública.Foi Inspetor Geral de Finanças da Secretaria de Fazenda do Estado do Rio de Janeiro. Atualmente é o Controlador Geral do Município do Rio de Janeiro.
} 
Dessa forma, deve o Poder Judiciário, ao exercer o controle jurisdicional, não se restringir ao exame estrito da legalidade do ato administrativo, mas, sim, entender por legalidade ou legitimidade não só a conformação do ato com a lei, como também com a moral administrativa e com o interesse coletivo.

Tal controle, pressupõe Silva (2002), está na existência de um único órgão de controle, a que denominamos CONTROLADORIA ou ÓRGAO CENTRAL DE CONTROLE INTERNO -nos moldes existentes em outros países, como nos Estados Unidos, onde o General Accounting Qffice (GAO) exerce, na esfera federal, as funções de controle desde 1921.

O princípio da moralidade está intimamente ligado com a idéia de probidade, dever inerente do administrador público. Como recorda Lopes $(2002)^{3}$, o velho e esquecido conceito do probus e do improbus administrador público está presente na Constituição da República, que pune a improbidade na Administração com sanções políticas, administrativas e penais.

A conduta do administrador público, em despeito aos princípios norteadores da Lei de Responsabilidade Fiscal e da moralidade administrativa, enquadra-se nos denominados atos de improbidade, a Lei $n^{0}$ 10.028/00 ${ }^{4}$ permite ao Ministério Público a propositura de ação civil pública por ato de improbidade, enquanto a Lei $n^{\circ} 8.429 / 92^{5}$ permite ao Poder Judiciário o controle jurisdicional sobre lesão ou ameaça de lesão ao patrimônio público.

O administrador público precisa ser eficiente, ou seja, deve ser aquele que planeja $\mathrm{o}$ orçamento pautado pela obediência à objetividade e à imparcialidade. Igualmente, é aquele que produz o efeito desejado da execução orçamentária, que dá bom resultado, exercendo suas atividades sob o manto da igualdade de todos perante a lei.

O orçamento público surgiu, como instrumento administrativo, na Inglaterra no ano de 1822. Constituía-se num modo da sociedade impor uma limitação aos gastos públicos, evitando os sucessivos e crescentes aumentos

\footnotetext{
${ }^{3}$ Promotor de Justiça da Infância e da Juventude, em São Paulo

${ }^{4}$ Projeto de Lei n. 621/99, de autoria do Poder Executivo, que altera e acresce dispositivos ao Decreto-lei n. ${ }^{\circ} 2.848$, de 7 de dezembro de 1940 - Código Penal, à Lei n. 1.079, de 10 de abril de 1950, e ao Decretolei $\mathrm{n}^{\circ} 201$, de 27 de fevereiro de 1967, e dá outras providências.
} 
de tributos. Por isso, é natural que o orçamento esteja ligado ao controle sobre a ação administrativa e a definição da responsabilidade fiscal.

Orçamento nasceu como instrumento de controle - controle da sociedade sobre a administração pública; na essência, é o espírito da ação democrática que é sentido. Nada é mais relevante do que permitir ao povo que imponha ao governante limite ao direito de arrecadar, em nome do povo e para o povo.

É de vital importância ressaltar o caráter instrumental imposto pelo orçamento e que este não é um fim em si mesmo, mas uma ferramenta, sem a qual não se administra. O orçamento inter-relaciona e interage com diversos campos do conhecimento, entre eles podemos citar a Contabilidade, a Economia, o Direito, a Administração.

O impulso dado na implementação do regime orçamentário e fiscal brasileiro atual é uma marca da política econômica dos últimos anos, constituindo-se um importante apoio para o atual cenário de crescimento econômico. Seguido de estabilidade de preços, este crescimento passou a ser auto-sustentável. Além da melhora nos resultados orçamentários e fiscais, significando um maior comprometimento com resultados para a sociedade, várias foram as mudanças institucionais, com o objetivo não só de permitir a solvência do setor público a longo prazo, por meio da estabilização do endividamento público, mas também de aumentar a transparência fiscal, haja vista a importância dada ao planejamento orçamentário.

As previsões orçamentárias atuais são peças criadas após o advento da Lei de Responsabilidade Fiscal que se propõe a diminuir os riscos que afetam o cumprimento de metas de resultados.

Com relação aos riscos orçamentários, a Lei de Responsabilidade Fiscal, no seu art. $^{\circ}$ prevê que, se ao final de um bimestre, a realização da receita não comportar o cumprimento das metas de resultados estabelecidas no Anexo de Metas Fiscais, os Poderes e o Ministério Público promoverão, por ato próprio e nos montantes necessários, nos trinta dias subseqüentes,

\footnotetext{
${ }^{5}$ Dispõe sobre as sanções aplicáveis aos agentes públicos nos casos de enriquecimento ilícito no exercício de mandato, cargo, emprego ou função na administração pública direta, indireta ou fundacional e dá outras providências. (DOU 03.06.1992).
} 
limitação de empenho e movimentação financeira. Este mecanismo permite que desvios em relação às previsões sejam corrigidos ao longo do ano de forma a não afetar o cumprimento das metas de resultado.

Dessa forma, a Lei de Diretrizes Orçamentárias estabelecerá as prioridades e metas da administração pública, a estrutura e organização dos orçamentos, as diretrizes para execução dos orçamentos e as disposições sobre alterações na legislação tributária, baseados no planejamento previsto no Plano Plurianual.

A Lei de Orçamento discriminará a Receita e a Despesa previstas para o próximo exercício financeiro (01 de janeiro - 31 de dezembro), de forma a evidenciar a política econômico-financeira e o programa de trabalho do Governo. O Governo define no Projeto de Lei Orçamentária as prioridades contidas no Plano Plurianual - PPA e as metas que deverão ser atingidas naquele ano. A Lei Orçamentária disciplina todas as ações do governo nas esferas Federal, Estadual e Municipal.

A visualização do processo de integração das leis orçamentárias apresenta-se na figura abaixo :

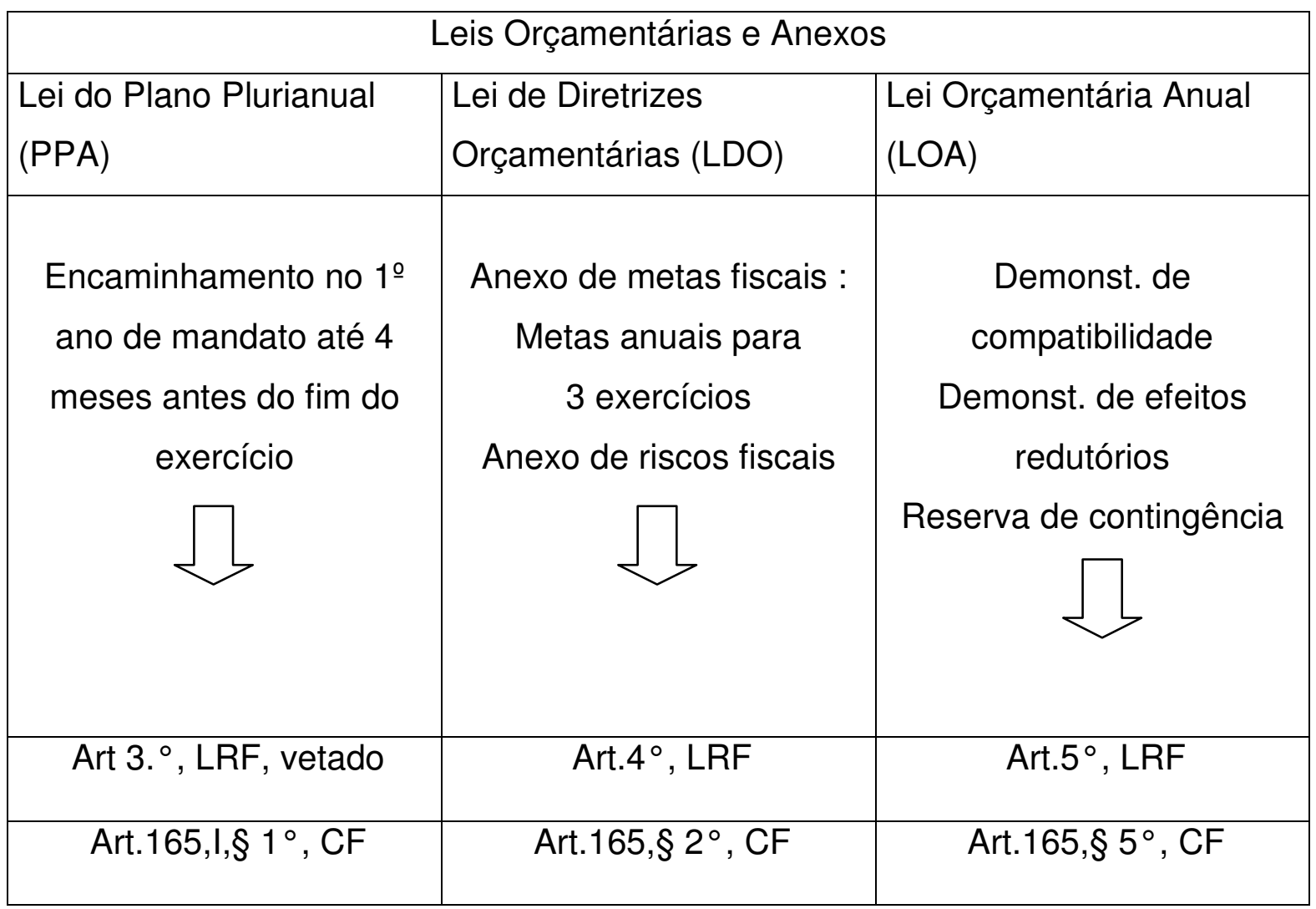




\begin{tabular}{|c|c|c|}
\hline Art. $35, \S 2^{\circ}$, ADCT & \\
União : Lei ${ }^{\circ} .9 .989 / 00^{\varsigma}$ & União : Lei $n^{\circ} .9 .995 / 00^{ð}$ & União : Lei $n^{\circ} .10 .171 / 01^{8}$ \\
\hline
\end{tabular}

Figura 1 - Leis Orçamentárias e Anexos

Fonte: MOTTA, Carlos Pinto Coelho. Responsabilidade Fiscal, Lei

Complementar 101.

\section{CONTROLADORIA PÚBLICA}

Quando vamos para o artigo 74, conforme cita Silva (2002), observamos que os Poderes Judiciário, Executivo e Legislativo têm sistemas de controle interno, contrariando dispositivos da Constituição anterior, que dizia que só ao Poder Executivo incumbia a função de controle interno. Esses sistemas de controle interno são geradores de informações da execução orçamentária e, portanto, de demonstrações de contabilidade.

As demonstrações aludidas vão para um órgão central de controle que denominamos Controladoria, a qual assume o papel de fazer a integração dos controles dos demais Poderes. Ressalte-se que este procedimento é levado a efeito na estrutura governamental do Município do Rio de Janeiro. Evidentemente, essa Controladoria é um órgão de apoio institucional ao Tribunal de Contas, citada pela Constituição Federal.

$\mathrm{Na}$ década de 60, foi aprovada uma reforma administrativa federal, cujo documento mais relevante foi o Decreto-lei $n$ - 200/67, no qual o sistema de controle interno experimentou uma mudança significativa, passando a dar ênfase ao processo de fiscalização financeira, surgindo, então, no lugar da Contadoria Geral da República, as Inspetorias Gerais de Finanças, como órgãos do sistema de administração financeira, contabilidade e auditoria (Silva 2002, p205).

\footnotetext{
${ }^{6}$ (DOU 24.07.2000)

Dispõe sobre o Plano Plurianual para o período de 2000/2003.União

${ }^{7}$ (DOU 26.07.2000)

Dispõe sobre as diretrizes para a elaboração da lei orçamentária de 2001 e dá outras providências.União

${ }^{8}$ (DOU 08.01.2001, ret. DOU 09.01.2001, DOU 13.07.2001, DOU 11.10.2001 e DOU 15.10.2001)

Estima a Receita e fixa a Despesa da União para o exercício financeiro de 2001.União
} 
Conforme Silva (2002), com a edição da Constituição de 1988, embora os aspectos da legalidade e da formalidade ainda permaneçam como focos culturalmente importantes por parte dos órgãos de controle interno e externo, constatam-se diversas experiências inovadoras em que os sistemas tradicionais estão sendo gradativamente abandonados e, conseqüentemente, a contabilidade e a auditoria passam a estar mais voltadas para aspectos gerenciais.

No âmbito municipal, cabe destacar que, em 1993, o Município da Cidade do Rio de Janeiro aprovou a lei de criação da Controladoria Geral do Município, com nível de Secretaria Municipal diretamente subordinada ao Prefeito, que aglutinou em sua estrutura as funções de Contabilidade e Auditoria e tem como atribuições principais exercer os controles contábil, financeiro, orçamentário, operacional e patrimonial de toda a administração municipal, zelar pela eficiência da aplicação das receitas públicas e apoiar o Tribunal de Contas (Silva 2002, p. 207)

Neste modelo municipal criado no município do Rio de Janeiro, segundo Silva (2002), desde sua implantação, a Controladoria tem desenvolvido projetos de controle preventivo com o objetivo de tornar a administração transparente, reduzir os gastos públicos e promover a eficiência e a eficácia das atividades da Prefeitura.

Sobre o tema, Lino (2002, p. 209) cita como significativa à opinião de Antonino M. Trevisan, Publicada no Boletim do Auditor do Audibra, № 25, p. 9, out. 1986, a seguir transcrita:

"Nas empresas americanas, o 'controller' é quase urna extensão do braço da alta administração, quer dizer, o braço armado dos diretores executivos da empresa. Então, a função abrange todas as áreas financeiras -exceto a tesouraria, para evitar conflito de funções - e tudo que seja controle operacional da empresa. Contabilidade comercial e gerencial, custos e orçamentos, planejamento e a parte de auditoria interna normalmente se enquadram na pessoa e no trabalho do 'controller'". 


\section{PLANEJAMENTO}

O planejamento é inerente à atividade administrativa, e, no Brasil, há décadas, encontra-se entre os princípios legais que estruturaram a reforma administrativa levada a efeito pelo Decreto-lei 200, de fevereiro de $1967^{9}$. Desde então, recursos públicos, orçamento e gestão deveriam estar compatibilizados entre si, estruturando o desenvolvimento socioeconômico do País.

A terminologia mudou de Plano Geral de Governo e Orçamento Anual para os atuais Plano Plurianual - PPA, Lei de Diretrizes Orçamentárias - LDO e Lei Orçamentária Anual - LOA. Os programas de governo devem, assim, iniciar, a partir da quantificação financeira de metas e objetivos, por períodos de tempo, exigindo-se uma mudança de mentalidade, no sentido de se assegurar a continuidade de programas, independentemente de períodos de governo.

$\mathrm{Na}$ implementação do sistema de controle interno-integrado, como preconizado na Constituição Federal, é fundamental entender que a contabilidade e a auditoria devem estar vinculadas ao órgão central de controle, a que denominamos de CONTROLADORIA ou CONTADORIA E AUDITORIA GERAL, pois, assim, o controle passará a abandonar, de modo gradual, o exame das formalidades para direcionar seus esforços ao exame e análise dos aspectos finalísticos. As experiências já adotadas nesse particular revelam que um sistema de controle com tal estrutura tem mais facilidade de gerar relatórios sobre a economicidade, a eficiência e a eficácia das ações de governo.

Portanto, na implantação da Controladoria, segundo as normas constitucionais, tem de constar, entre outras, as seguintes atribuições:

- prestação de contas apresentadas anualmente pelo Governo ao Poder Legislativo, por meio do Tribunal de Contas;

- servir, por meio de documentos e relatórios, de instrumento de auxílio no processo decisório;

\footnotetext{
${ }^{9}$ Art6. ${ }^{\circ}$, inc. I
} 
- produzir avanços no uso dos sistemas tradicionais de controles orçamentário, financeiro e patrimonial, estabelecendo um elenco de indicadores financeiros, econômicos e sociais que permitam a melhoria do processo decisório.

\section{LEGISLAÇÃO}

\subsection{LEI DE RESPONSABILIDADE FISCAL}

A Constituição de 1988 tornou obrigatórios alguns instrumentos básicos de planejamento e a Lei de Responsabilidade Fiscal reúne, em um único dispositivo, normas de Planejamento, Orçamento, Receita, Despesa, Dívida Pública e Endividamento. É uma Lei que busca, principalmente, o Controle dos atos da Administração Pública.

O intuito da Lei de Responsabilidade Fiscal é a gestão fiscal responsável, que deverá ocorrer mediante cuidadoso planejamento, cuja execução busque o equilíbrio das contas públicas, a prevenção de riscos, a correção de desvios verificados em sua execução, o cumprimento de metas propostas e, principalmente, a transparência de todos os atos da Administração Pública.

A Lei de Responsabilidade na Gestão Fiscal foi editada para regulamentar os artigos 163, 165, 167 e 169 da Constituição Federal. Esta Lei é dirigida aos Entes Políticos (União, Estados-membros, Distrito Federal, e Municípios); aos três Poderes que exercem as funções Executiva Legislativa e Judiciária; a todos os Órgãos da Administração Direta e Indireta (Autarquia, Fundações, Fundos); a todas as Estatais controladas e dependentes (assim entendidas as que recebem, do órgão Político a que estão vinculadas, recursos financeiros para o custeio); ao Ministério Público; aos Tribunais de Contas (da União, dos Estados e dos Municípios - onde houver, exemplo: cidade de São Paulo)

Com relação ao Planejamento, prevê a Lei de Responsabilidade Fiscal a obrigatoriedade de elaboração de quatro anexos, que deverão acompanhar a Lei de Diretrizes Orçamentárias - LDO. São eles: o Anexo de Metas Fiscais, o 
Anexo de Riscos Fiscais, o Anexo de Compatibilidade do Orçamento com os objetivos e as metas fiscais e, finalmente, o Anexo de Política Econômica (obrigatório somente para a União).

Com efeito, outros têm sido utilizados para um melhor desempenho das ações de planejamento municipal. O objetivo de se levantar tais informações é de verificar com quais instrumentos os municípios efetivamente estão trabalhando, com a finalidade de melhor elaborar o planejamento municipal.

A Lei de Responsabilidade Fiscal trouxe um novo horizonte e, também, adptou-se à nova normatização da lei de crimes contra a administração pública - lei $n^{\circ} 10028 / 00$.

A par das sanções administrativas previstas no corpo da Lei Complementar 101/00, tais como a que fulmina de nulidade determinados atos, quando praticados em detrimento da boa e regular gestão de recursos públicos (despesa de pessoal, desapropriação de imóvel urbano sem observância do disposto no art. 182, § $3^{\circ}$ da Constituição Federal), ou ainda, a que veda 0 recebimento de transferências voluntárias de outros entes políticos e realização de operações de crédito, dentre outras, o art. 73 prevê a responsabilização pessoal dos Agentes Públicos.

$\mathrm{Na}$ maioria das vezes, o executivo municipal desconhece o que é orçamento, deixando a cargo das Secretarias de Finanças a incumbência da preparação orçamentária.

Na condição de responsável, o executivo municipal deve ter presente o que a Lei considera como crime de responsabilidade:

- deixar de ordenar a redução do montante da dívida consolidada, nos prazos estabelecidos em lei (Lei Complementar 101/00), quando o montante ultrapassar o valor resultante da aplicação do limite máximo fixado pelo Senado Federal;

- ordenar ou autorizar a abertura de crédito em desacordo com os limites estabelecidos pelo Senado Federal, sem fundamento na lei orçamentária ou na de crédito adicional ou com inobservância de prescrição legal; 
- deixar de promover ou de ordenar, na forma da lei, o cancelamento, a amortização ou a constituição de reserva para anular os efeitos de operação de crédito realizada com inobservância de limite, condição ou montante estabelecido em lei;

- deixar de promover ou de ordenar a liquidação integral de operação de crédito por antecipação de receita orçamentária, inclusive os respectivos juros e demais encargos, até o encerramento do exercício financeiro;

- ordenar ou autorizar, em desacordo com a lei, a realização de operação de crédito com qualquer um dos demais entes da Federação, inclusive suas entidades da administração indireta, ainda que na forma de novação, refinanciamento ou postergação de dívida contraída anteriormente;

- captar recursos a título de antecipação de receita de tributo ou contribuição, cujo fato gerador ainda não tenha ocorrido;

- ordenar ou autorizar a destinação de recursos provenientes da emissão de títulos para finalidade diversa da prevista na lei que a autorizou;

- realizar ou receber transferência voluntária em desacordo com limite ou condição estabelecida em lei.

A Lei de Responsabilidade Fiscal está apoiada em quatro grandes eixos: planejamento, transparência, controle e responsabilização.

\begin{tabular}{||l||l||}
\hline \multicolumn{1}{|c||}{ Princípios } & \multicolumn{1}{c||}{ Fundamentos } \\
\hline \hline \multirow{2}{*}{ Não gastar mais do que arrecadar } & Permitir planejamento fiscal \\
Não se endividar mais do que a & Consistente \\
capacidade de pagar & Tornar gestão fiscal transparente \\
Escolher corretamente os gastos & Criar instrumentos de controle social \\
prioritários & eficazes e democráticos \\
Combater o desperdício & Responsabilizar e punir o mau \\
\hline
\end{tabular}

Figura 2 - Princípios norteadores da LRF 
Fonte: Adaptado : MOTTA, Carlos Pinto Coelho. Responsabilidade Fiscal, Lei complementar 101.

No planejamento, devem ser estabelecidas informações, metas, limites e condições para: renúncia de receita; geração de despesas; despesas com pessoal e da seguridade; dívidas e operações de crédito, antecipação de receita orçamentária e concessão de garantias.

No eixo da transparência, a Lei prevê ampla divulgação, inclusive pela Internet, de quatro novos relatórios de acompanhamento da gestão fiscal, que permitem identificar receitas e despesas - possibilitando maior acesso às contas públicas por parte do contribuinte.

A transparência fiscal inclui ainda audiências públicas na Câmara de Vereadores, sempre que o Executivo enviar os relatórios quadrimestrais de cumprimento de metas.

Aprimorado pela maior transparência e qualidade das informações, o controle exigirá uma ação fiscalizadora mais efetiva e permanente. Lino Martins alerta para a necessidade de os gestores conhecerem princípios e normas básicas da Lei. "É importante que escolham assessores e técnicos para estudar a legislação em profundidade, além de determinar ao controle interno atenção redobrada na elaboração e nos prazos de divulgação das novas formas de prestação de contas".

Os modelos de relatórios de execução orçamentária referentes às exigências da LRF têm sido divulgados pela internet, através dos tribunais de contas, conforme figura abaixo :

Mês de Referência: 2002/07 (valores correspondentes aos últimos doze meses)

\begin{tabular}{llrr} 
& \multicolumn{1}{c}{ Descrição } & \multicolumn{1}{c}{$\mathbf{R} \$$} & $\%$ RCL \\
\hline & Receita Corrente Líquida - & $27.003 .814,8$ & \\
RCL & 2 & \\
& & $32.010 .907,1$ & 118,54 \\
& Dívida & 1 & \\
& & $32.010 .907,1$ & 118,54 \\
& Consolidada & 1 &
\end{tabular}




\begin{tabular}{|c|c|c|c|}
\hline & Mobiliária & 0,00 & 0,00 \\
\hline \multirow[t]{2}{*}{8} & Pessoal (Total) & $\begin{array}{r}13.808 .278,7 \\
8\end{array}$ & 51,13 \\
\hline & Legislativo & $410.300,76$ & 1,52 \\
\hline \multirow[t]{2}{*}{9} & Executivo & $\begin{array}{r}13.397 .978,0 \\
2\end{array}$ & 49,62 \\
\hline & Administração Direta & $\begin{array}{r}12.848 .469,9 \\
3\end{array}$ & 47,58 \\
\hline & Administração Indireta & $549.508,09$ & 2,03 \\
\hline 10 & Concessões de Garantias & 0,00 & \\
\hline 11 & $\begin{array}{l}\text { Antecipação de Receitas } \\
\text { Orçamentárias }\end{array}$ & 0,00 & \\
\hline 12 & Restos a Pagar & $825.408,51$ & \\
\hline
\end{tabular}

Figura 3 - Comparativo do Cumprimento dos Limites da Lei de

\section{Responsabilidade Fiscal - LRF - Município X}

Fonte: Adaptada, http://sis.tce.rs.gov.br:8084/sis/gfiscal/consulta gfiscal TCE /RS

O quarto eixo da Lei - a responsabilização - deverá ocorrer sempre que houver descumprimento das regras, com a suspensão de transferências voluntárias, garantias e contratações de operações de crédito, inclusive antecipação de receita orçamentária. As penalidades previstas vão desde multa sobre os vencimentos anuais até detenção e cassação do mandato.

O governante deverá estar atento para que nenhum gasto seja realizado sem planejamento orçamentário ou eventuais compensações com aumento permanente de receita ou redução permanente de despesa. Um dos principais méritos da Lei de Responsabilidade Fiscal é obrigar o administrador a manter atenção gerencial.

\subsection{LEI ORGÂNICA MUNICIPAL}

A Lei Orgânica Municipal é o conjunto de leis básicas de cada município e passou a ser de formulação obrigatória a partir da Constituição Federal de 1988 "Art. 29. O Município reger-se-á por lei orgânica, votada em dois turnos, 
com o interstício mínimo de dez dias, e aprovada por dois terços dos membros da Câmara Municipal, que a promulgará, atendidos os princípios estabelecidos nesta Constituição, na Constituição do respectivo Estado e os seguintes preceitos : [...] - XII - cooperação das associações representativas no planejamento municipal; (inciso renumerado pela Emenda Constitucional oㅡ 01/92)

Segundo o Instituto Brasileiro de Geografia e Estatística - IBGE, verificase que no Brasil 96,4\% dos municípios possuem Lei Orgânica, sendo que, na faixa acima de 200 mil habitantes, ela existe em 100\% dos municípios.

Relativamente à data da Lei Orgânica, ressaltam-se os altos percentuais de promulgação com até dez anos, refletindo a fase em que esta legislação passou a ser obrigatória. Pesquisa IBGE (2002) cita que no grupo dos municípios instalados em 1997, ou seja, nos de criação recentíssima, o percentual de existência da Lei Orgânica cai para 88, 1 \%, o que é explicável, pois muito destes municípios ainda não tiveram tempo para se adequarem à lei.

\section{INSTRUMENTOS DE PLANEJAMENTO MUNICIPAL}

\subsection{PLANO PLURIANUAL}

De acordo com a Constituição Federal, o Projeto de Lei do Plano Plurianual - PPA deve conter "as diretrizes, objetivos e metas da administração pública federal para as despesas de capital e outras delas decorrentes e para as relativas aos programas de duração continuada". O PPA estabelece a ligação entre as prioridades de longo prazo e a Lei Orçamentária Anual.

O Projeto de Lei do PPA define as prioridades do governo por um período de quatro anos e deve ser enviado pelo Presidente da República ao Congresso Nacional até o dia 31 de agosto do primeiro ano de seu mandato.

O Art. 165, § 2, no capítulo II - Finanças Públicas, da Constituição Federal cita "o plano plurianual estabelecerá, de forma regionalizada, as diretrizes, objetivos e metas da administração pública federal para as despesas 
de capital e outras delas decorrentes e para as relativas aos programas de duração continuada". Neste artigo destaca-se, ainda :

"I - o plano plurianual;

II - as diretrizes orçamentárias;

III - os orçamentos anuais.

$[\ldots]$

§ 3‥ O Poder Executivo publicará, até trinta dias após o encerramento de cada bimestre, relatório resumido da execução orçamentária. ${ }^{10}$

$\S 4^{\circ}$. Os planos e programas nacionais, regionais e setoriais previstos nesta Constituição serão elaborados em consonância com o plano plurianual [...]

[...]

§ 6․․ O projeto de lei orçamentária será acompanhado de demonstrativo regionalizado do efeito, sobre as receitas e despesas, decorrente de isenções, anistias, remissões, subsídios e benefícios de natureza financeira, tributária e creditícia.

$\S 7^{\circ}$. Os orçamentos [...] serão compatibilizados com o plano plurianual, terão entre suas funções a de reduzir desigualdades inter-regionais, segundo critério populacional.

$[\ldots]$

§ 9․ Cabe à lei complementar:

I - dispor sobre o exercício financeiro, a vigência, os prazos, a elaboração e a organização do plano plurianual, da lei de diretrizes orçamentárias e da lei orçamentária anual;

II - estabelecer normas de gestão financeira e patrimonial da administração direta e indireta, bem como condições para a instituição e funcionamento de fundos."

\subsection{LEI DE DIRETRIZES ORÇAMENTÁRIAS}

Inserida na Constituição Federal de 1988, a exemplo das constituições da França e Alemanha, a Lei de Diretrizes Orçamentárias possui a finalidade 
de servir como uma espécie de pré-orçamento, como um instrumento de planejamento que deve servir como um elo entre o plano plurianual - PPA e a lei orçamentária anual - LOA.

A Lei de Diretrizes Orçamentárias tem seu escopo delineado na Constituição da República (art. 165, § 2º) e possui objetivo de definir e quantificar metas físico-financeiras, de acordo com os programas e ações previamente previstos no PPA; estabelecer prioridades na execução do orçamento de um exercício; estabelecer a política tributária e de pessoal para o exercício seguinte e a política de aplicação das agências financeiras oficiais de fomento e, por fim, o objetivo de traçar orientações à lei orçamentária para a manutenção ou o alcance do equilíbrio fiscal (de receitas e despesas) e, em conseqüência, das contas públicas.

A função básica da Lei de Diretrizes Orçamentárias é a de definir as prioridades a serem executadas e, também, de nortear sobre as alterações na política tributária e de pessoal, bem como estabelecer alguns critérios no funcionamento da administração, tais como: avaliação de resultados, sistemas de custos, definição de despesas irrelevantes, aplicabilidade da reserva de contingência e outros que se fizerem necessários para orientar a administração nos seus atos pertinentes à elaboração e à execução do orçamento anual. Existem ainda outras funções como:

a) O poder Executivo deve disponibilizar a previsão da receita, nos termos do art. 12 da LRF, para o exercício de 2003, para que possa o Legislativo elaborar a sua proposta orçamentária, nos termos do art. 12 da LRF. Observe-se que apesar de 0 art. 12, § $3^{\circ}$, da LRF, se referir à proposta orçamentária, não deve ser somente na lei orçamentária a ocorrência deste procedimento. A idéia de que o orçamento é integrado e se constitui em um processo, sendo que em todas as suas fases deve ser revista a previsão de receita, nos leva a uma interpretação sistêmica, mais abrangente, e que contempla todo o processo orçamentário e que seja condizente com os princípios da própria LRF arrolados no art. $1^{\circ}$ da Lei. Além disso, o art. 12, que se

\footnotetext{
${ }^{10}$ Em cumprimento ao que dispõem os artigos 52 e 53 da Lei Complementar $n^{\circ} 101$, de 04 de maio de
} 
refere à estimativa de receita, não se vincula ao PPA, à lei de diretrizes orçamentárias ou à lei orçamentária anual, perfazendo-se em capítulo desvinculado de qualquer etapa do processo de planejamento;

b) O poder Legislativo, após elaborar a sua proposta, deverá encaminhá-la, para fins de integração, ao Executivo;

c) as audiências públicas devem ser realizadas pelo Poder Executivo (fase da elaboração) e pelo Poder Legislativo (fase da discussão). As audiências devem ser regulamentadas em cada Poder e o edital deve dar conhecimento à população sobre a realização da(s)s audiência(s). No Executivo a regulamentação se dá por decreto e no Legislativo por resolução. Como a lei de diretrizes se referirá ao exercício de 2003 e deverá conter os programas e ações para aquele exercício, nada mais natural que seja realizada a audiência pública conjunta do orçamento anual, por se tratar da mesma matéria, todavia, imperioso que tal referência deva ser feita;

d) Como o Poder Executivo submete-se aos conselhos municipais para a escolha de diretrizes e estratégias da aplicação de recursos destinados, por exemplo, à saúde (com poder inclusive de deliberação), educação, meio-ambiente, assistência social, agricultura e outros, é natural que, para um planejamento sério, os conselhos sejam chamados para a elaboração e discussão (no Legislativo nas audiências) da LDO, como condição de eficácia para o planejamento e validação do processo.

A LDO deverá dispor,ainda, sobre:

i) Transferências dos recursos ao Legislativo;

ii) cronograma de desembolso financeiro;

iii) reserva de Contingência;

iv) critérios e formas de limitação de empenho em caso de não atingimento das metas fiscais e endividamento (só os 
municípios com mais de 50.000 habitantes), bem como as contas em que não poderão ser limitados empenhos;

v) condições para transferências de recursos a entidades (todos) - A LDO deverá estabelecer as condições, de maneira impessoal, para que possa o município transferir recursos a entidades. Não pode a LDO, e tampouco o orçamento, conter nomes de entidades. Importante referir que, para a transferência de recursos para fundos e fundações, cuja finalidade seja cobrir déficits de manutenção, necessitará de lei específica, conforme determina a CF, art. 167, VIII;

vi) Normas relativas a sistemas de custos e avaliação dos resultados dos programas de governo. Sobre os custos, primeiro os municípios devem se preocupar com o controle interno, depois custos. Não a como se falar em custos sem controles internos fortes. Sobre a avaliação de resultados dos programas de governo, esta se refere não há resultados fiscais, não se fez determinada obra ou não, mas, sim, ao andamento dos indicadores de desempenho. Este item em nada tem a ver com as audiências públicas de que trata $o$ art. $9^{\circ}$, § $4^{\circ}$ da LRF;

vii) definição de despesa irrelevante para fins do art. 16 da LRF criação, expansão e aperfeiçoamento da ação governamental (art. 16, § 3ㅇ);

viii) previsão dos casos em que será possível a realização de horas extras se ultrapassados os limites de pessoal (art. 22, § único, V);

ix) condições para transferências pessoas físicas e jurídicas (art. 26);

x) condições para o início de novos projetos, priorizando os já em andamento e as despesas de manutenção (art. 45);

xi) custeio de despesas de outros entes - art. 62; 
xii) forma de utilização da margem de expansão das despesas obrigatórias de caráter continuado.

\subsection{LEI ORÇAMENTÁRIA ANUAL}

É especialmente por meio de programas que os Governos Federal, Estadual e Municipal, através das peças orçamentárias - PPA, LDO e LOA, promovem o atendimento das demandas sociais e o desenvolvimento da infraestrutura econômica, no intuito de melhorar as condições de vida da população brasileira e proporcionar a base para o crescimento sustentado da atividade produtiva.

O Decreto-lei $n^{\circ} 200$, de 25 de fevereiro de 1967, estruturou por bom tempo a reforma administrativa e, desde então, recursos públicos, orçamento e gestão deveriam estar compatibilizados entre si, estruturando o desenvolvimento socioeconômico do País, apresentando-se tão somente como plano geral de governo e orçamento-programa anual.

A dinâmica dos tempos trouxe-nos a necessidade de uma terminologia adequada às mudanças e os programas de governo passaram a estruturar-se como sendo o elo determinante entre as demais peças orçamentárias.

Observadas as situações do Plano Plurianual de Investimentos, da Lei de Diretrizes Orçamentárias e da Lei de Orçamento Anual, legislação obrigatória pelo artigo 165 da Constituição supramencionado, esperava-se encontrar um alto percentual de municípios que afirmasse dispor destes instrumentos, o que realmente acorreu com relação às Leis de Diretrizes Orçamentárias e do Orçamento Anual, que apresentam altíssimos percentuais de implantação em todas as faixas de população de município, chegando a atingir segundo estudos do IBGE, 100\% em algumas faixas. Apenas 6,2\% e $5,1 \%$ dos municípios não dispõem da Lei de Diretrizes Orçamentárias e da Lei de Orçamento Anual, respectivamente. O Plano Plurianual de investimentos, entretanto, embora exista também na maioria dos municípios brasileiros 
$(81,1 \%)$, apresenta percentuais de implantação inferiores em municípios de todas as faixas de população.

É interessante notar, ainda, que nos municípios criados mais recentemente, ou seja, que foram instalados em 1997 e, portanto, estavam em sua primeira gestão no momento da realização da pesquisa, o cumprimento desta legislação obrigatória encontra-se presente em um percentual menor de municípios. O Plano Plurianual de investimentos não existia em 22,4 \% dos municípios instalados em 1997, enquanto as Leis de Diretrizes Orçamentárias e as de Leis Orçamentárias Anuais não foram implementadas em 8,7\% e 8,5\% destes municípios, respectivamente. Estes fatos são esperados, pois os municípios, em suas primeiras gestões, apresentam dificuldades de se adequarem a todas as regulamentações necessárias.

Quando se observam os dados dispostos no grande cenário nacional nas grandes regiões, destacam-se Norte e Nordeste como aqueles onde os percentuais de implementação da legislação básica em seus municípios apresentam-se mais baixos.

Embora não sejam de implementação obrigatória, o plano de governo ou plano de Diretrizes Governamentais e o plano estratégico são desejáveis no sentido de propiciarem um melhor planejamento governamental.

O plano de governo, já de longa data implementado no Brasil por várias gestões municipais, só foi registrado em cerca de $35,8 \%$ dos municípios existentes em 1999. Quando se observam os municípios, segundo o tamanho da população, os dados são bastante significativos, pois os municípios mais populosos, acima de 50.000 mil habitantes, com maior freqüência têm Plano de Governo, chegando a 83,3\% nos município de mais de 1 milhão de habitantes.

O plano estratégico, de implementação mais recente no País, foi encontrado em apenas 6,5\% dos municípios. Quando se observam os dados por tamanho de municípios, verifica-se que, também neste caso, os percentuais de municípios que elaboraram planos estratégicos são maiores nas faixas de população acima de 50 mil habitantes, chegando a um terço dos municípios na faixa de 1 milhão. 


\section{INSTRUMENTO DE GESTÃO URBANA}

Este grupo de informações objetiva verificar a situação dos municípios relativamente à gestão urbana, através da situação dos diversos instrumentos de regulação, desde os mais gerais, como plano diretor, perímetro urbano, zoneamento, parcelamento, código de obras e de postura, até os mais específicos como a legislação sobre áreas de interesse especial e social, o solo criado, o IPTU progressivo, operações interligadas, operações urbanas e transferências do potencial construtivo.

A expectativa com relação aos dados sobre os instrumentos de gestão urbana nos municípios brasileiros era de que seriam mais freqüentes nos municípios de maior porte populacional, onde os problemas de gestão urbana tendem a ser mais críticos e, portanto, instrumentos de regulação são mais necessários De uma maneira geral os dados encontrados pelo censo IBGE confirmam esta tendência e revelam a necessidade de se estender à regulação para gestão urbana a um número muito maior de municípios do que aqueles onde ela já existe. O plano diretor passou a ser obrigatório, desde a constituição de 1988, para todos os municípios com mais de 20 mil habitantes. Tomando-se o conjunto de municípios brasileiros apenas cerca de 15\% possuem Plano-Diretor. Entretanto, acima do patamar populacional estabelecido, ainda é grande o percentual de municípios que não dispõem de plano diretor, contrariando as expectativas.

Segundo as faixas de população, conforme vai crescendo o porte, são encontrados percentuais maiores de municípios que possuem plano diretor. $\mathrm{Na}$ faixa populacional entre 20 e 50 mil habitantes, apenas $20,6 \%$ dos municípios possuem plano diretor.

\section{CONCLUSÃO}

Municípios como o do Rio de Janeiro já se encontram bastante avançados quanto à função do Controller. Sua função abrange: controle interno e suas diversas operações nas esferas executiva, legislativa, exceto no 
judiciário em nível municipal. Será necessário investir nos municípios para a modernização e eficiência de seus controles

A nova situação apresentada após a Lei levou o Governo Federal, através do Ministério do Planejamento, Orçamento e Gestão, em parceria com - BNDES, a dar apoio técnico aos municípios brasileiros. Foram disponibilizadas linhas de crédito aos prefeitos dentro do Programa de Modernização da Administração Tributária e de Gestão dos setores sociais básicos - PMAT - que vem alcançando grande receptividade junto a prefeituras de todos os tamanhos e regiões do País.

O auxílio do Governo Federal representa esperança de que estejamos mais próximos da boa gestão pública, ou seja, equilíbrio das contas públicas, correção de desvios verificados na execução orçamentária, cumprimento das metas propostas, à transparência de todos os atos da administração pública e, principalmente, funcionamento de uma controladoria eficiente e eficaz.

\section{REFERÊNCIAS BIBLIOGRÁFICAS}

BANDEIRA DE MELLO, Celso Antônio. Curso de Direito Administrativo. 11. ed. São Paulo: Malheiros, 1999.

BASTOS, Celso Ribeiro. Lei complementar: teoria e comentários. São Paulo: Saraiva, 1985.

BASTOS, Celso Ribeiro e MARTINS, Ives Gandra. Comentários à Constituição do Brasil. 19. ed. São Paulo: Saraiva, 1995.

BRASIL.Lei complementar $n^{\circ} 101$, de 4 de maio de 2000. Lei de Responsabilidade Fiscal.

Lei $n^{\circ} 4.320$, de 17 de março de 1964. comentada. Rio de Janeiro: IBAM,2000/2001.

LOPES, Maurício Ribeiro. Improbidade do administrador público. Disponível em : <http:// www.jus.com.br/pecas>. Acesso em : 31 de ago 2002.

LEGISLAÇÃO. Disponível em:

< http://www.contabilidadegovernamental.com.br/legislação >.Acesso em: 07de jan 2002

MEIRELLES, Hely Lopes. Curso de direito administrativo. 18 ed. São Paulo: Malheiros, 1993. 
MODELO projeto de Lei LDO. Disponível em: <http://www.contabilidadegovernamental.com.br/modelo>. Acesso em: 31 de ago 2002

MOTTA, Carlos Pinto Coelho; FERNANDES, Jorge Ulisses Jacoby. Responsabilidade Fiscal: Lei Complementar 101 de 04/05/2000. 2.ed. Belo Horizonte: Del Rey, 2001.

PERFIL dos Municípios Brasileiros - Instituto Brasileiro de Geografia e Estatística IBGE - 2002 Disponível em: < http://www.ibge.gov.br>. Acesso em: 07 de jan 02

RELATÓRIOS de execução orçamentária. Disponível em: $<$ http://sis.tce.rs.gov.br:8084/sis/gfiscal/consulta>. Acesso em: 07 de jan 02 REVISTA do BNDES. Disponível em: <http://www.bndes.gov.br/conhecimento/publicações>. Acesso em 07 de jan 02.

REVISTA dos tribunais. Rio de Janeiro: Sono Press,2002. v.795 a 798, jan../abr. CD-ROM

SILVA, Lino Martins da. A necessidade da correta integração entre os controles interno e externo na administração pública. Revista Tribunal. Disponível em: http://www.tce.rj.gov.br/revista/artigos/r35c002.htm Acesso em 14de jan 02

,Lino Martins da. Contabilidade governamental: um enfoque administrativo. 5a.ed. São Paulo, 2002.

SOBRINHO, Manuel de Oliveira Franco. Da competência na atividade administrativa, Revista Tribunal. Disponível em: http://www.tce.rj.gov.br/revista/artigos/r35c001.htm Acesso em: 07 de jan 02 SANCHES, Oswaldo Maldonado. Dicionário de Orçamento, planejamento e áreas afins. Brasília. Prisma, 1997 